\title{
SIMULTANEOUS ESTIMATION OF SUMATRIRTAN SUCCINATE AND NAPROXEN SODIUM IN BULK DRUG AND PHARMACEUTICAL DOSAGE FORM BY RP-HPLC METHOD
}

\author{
*Gondalia Riddhi ${ }^{1}$, Dr. Abhay Dharamsi ${ }^{2}$ \\ ${ }^{1}$ Research Scholar, Bhagwant University, Ajmer, Rajasthan, India \\ ${ }^{2}$ Maliba Pharmacy College, Maliba campus, bardoli, Gujarat, Idia \\ *Corresponding author's E mail: rp_gondalia@yahoo.com Tel: 91-9924031437
}

\begin{abstract}
A simple, sensitive and rapid reverse phase high performance liquid chromatographic method was developed for simultaneous estimation of Sumatriptan succinate and Naproxen sodium. C18 column $(250 \mathrm{x} 4.6 \mathrm{~mm}, 5 \mu)$ was used with a mobile phase containing a mixture Acetonitrile: Methanol: phosphate buffer in the ratio of 50:10:40 at $\mathrm{pH}$ 6. The flow rate was $1.0 \mathrm{ml} / \mathrm{min}$ and effluents were monitored at $229 \mathrm{~nm}$ at flow rate of $1 \mathrm{ml} / \mathrm{min}$. The retention time was found to be $4.037 \mathrm{~min}$ for Naproxen sodium and $2.813 \mathrm{~min}$ for Sumatriptan Succinate. Calibration curve was plotted with a range from $1-5 \mu \mathrm{g} / \mathrm{ml}$ for Sumatriptan succinate and Naproxen sodium. The assay was validated for parameters like accuracy, precision, robustness and system suitability parameters. The proposed method can be useful in the routine analysis for determination on Sumatriptan succinate and Naproxen sodium.

Key words: Sumatriptan succinate, Naproxen sodium, Reverse Phase HPLC.
\end{abstract}

\section{INTRODUCTION}

Naproxen sodium (NAP) is chemically, (S)-6-methoxy- $\alpha$ methyl-2-naphthaleneacetic acid, sodium salt (Fig.1A). NAP is a non-steroidal anti-inflammatory drug (NSAID) commonly used for the reduction of moderate to severe pain, fever, inflammation and stiffness. It works by inhibiting both the COX-1 and COX-2 enzymes. Like other NSAIDs, naproxen is capable of producing disturbances in the gastrointestinal tract. Several chromatographic methods have been reported for determination of NS in raw material ${ }^{1}$, tablets ${ }^{2-4}$, plasma $^{5-7}$, urine $^{8}$, intestinal perfusion samples ${ }^{9}$ and pharmaceutical preparations ${ }^{10-11}$. Sumatriptan succinate (SUMA) is chemically, 3-[2-(dimethylamino)ethyl]-N-methyl-indole5- methanesulfonamide succinate (1:1) (Fig.1B). SUMA is a selective 5-hydroxytryptne1 receptor subtype agonist. Sumatriptan succinate is official in European Pharmacopoeia ${ }^{12}$ and United States Pharmacopoeia ${ }^{13}$, where chromatographic methods for sumatriptan succinate in bulk and tablet formulation were reported. Several analytical techniques like HPLC ${ }^{14-15}$ and LS-MS ${ }^{16-19}$ have been reported for sumatriptan succinate in combination with other drugs.

In recent years pharmaceutical preparations containing both these drugs have been available commercially. Although, many methods for estimation of NAP and SUMA individually have been reported in the literature, very few methods are available for their simultaneous determination, hence we have developed a simple HPLC spectrophotometric method for the simultaneous determination of NAP and SUMA in tablet dosage form.

\section{EXPERIMENTAL}

\section{Reagents:}

Gift samples of SUMA and NAP were procured from Sun Pharmaceutical Ltd., Vadodara, Gujarat. Commercially available Treximet tablets (containing $85 \mathrm{mg}$ SUMA and $500 \mathrm{mg}$ NAP) were obtained from GlaxoSmithKline. All other chemicals and solvents used were of HPLC grade.<smiles>COc1ccc2cc([C@@H](C)C(=O)O[Na])ccc2c1</smiles>

(A)<smiles>CNS(=O)(=O)Cc1ccc2[nH]cc(CCN(C)C)c2c1</smiles>

(B)

\section{Equipments and apparatus:}

A Shimadzu HPLC, CP224S analytical balance (Sartorius) and ultra sonic cleaner (Frontline FS 4) were used, Injector(Rheodyne,20 $\mu$ l), Sonicator, $\mathrm{pH}$ meter, Vaccum filter pump, Millipore filtration kit, mobile phase reservoir, Water bath, Sample filtration assembly and glassware's were used throughout the experiment.

\section{Chromatographic conditions:}


Analysis was carried at $229 \mathrm{~nm}$ using a C 18 column (Phenomenex-Gemini 250mm x 4.6mm, $5 \mu \mathrm{m}$ ) at ambient temperature. The mobile phase consisted of Acetonitrile: Methanol: phosphate buffer pH 6 (50:10:40 v/v) was set at a flow rate of $1.0 \mathrm{ml} / \mathrm{min}$.

\section{Preparation of Mobile phase:}

To $500 \mathrm{ml}$ of Acetonitrile, add $100 \mathrm{ml}$ of methanol and $400 \mathrm{ml}$ of phosphate buffer pH 6 were added. Then the mobile phase was degassed by sonicating for $20 \mathrm{~min}$.

\section{Diluent Preparation:}

Use the mobile phase as diluent.

\section{Standard Stock Solution (S1):}

Accurately weighed $2.5 \mathrm{mg}$ of Sumatriptan Succinate Working Reference Standard (WRS) was transferred into a $25 \mathrm{ml}$ volumetric flask. In the same flask accurately weighed $2.5 \mathrm{mg}$ of Naproxen sodium was added.

Then $15 \mathrm{ml}$ of mobile phase was added and mixed to dissolve.

Then it was diluted up to $25 \mathrm{ml}$. (100 $\mu \mathrm{g} / \mathrm{ml}$ of Sumatriptan Succinate and $100 \mu \mathrm{g} / \mathrm{ml}$ solution of Naproxen sodium)

\section{Preparation of sample solution:}

10 tablets (Treximet )were weighed and found to be $7.45 \mathrm{gms}$. Tablet powder weight equivalent to $4 \mathrm{mg}$ of Sumatriptan Succinate and $25 \mathrm{mg}$ Naproxen sodium was weighed and transferred into $50 \mathrm{ml}$ volumetric flask. The powder was first dissolved with a $20 \mathrm{ml}$ of mobile phase and sonicated for 15 minutes. Then filtered through Whattman filter paper, the filtrate was collected and the volume was made up to $50 \mathrm{ml}$ with the mobile phase. From this $1 \mathrm{ml}$ of the solution was taken and made up to $100 \mathrm{ml}$ with mobile phase to get concentration of $5 \mathrm{mcg} / \mathrm{ml}$ naproxen sodium and $0.8 \mathrm{mcg} / \mathrm{ml}$

\section{METHOD VALIDATION}

The chromatographic conditions were validated by evaluating specificity, linearity, accuracy, method and system precision, limit of detection (LOD), limit of quantification (LOQ), ruggedness, and robustness in accordance with ICH guideline Q2(R1)

\section{Linearity}

Standard stock solution was further diluted to obtain 1 $\mu \mathrm{g} / \mathrm{mL}, 2 \mu \mathrm{g} / \mathrm{mL}, 3 \mu \mathrm{g} / \mathrm{mL}, 4 \mu \mathrm{g} / \mathrm{mL}, 5 \mu \mathrm{g} / \mathrm{mL}, 6 \mu \mathrm{g} / \mathrm{mL}$ of Sumatriptan Succinate and Naproxen sodium in combination Twenty microlitre of the each standard solution was injected and chromatograms were recorded.

\section{Method and system precision}

Precision of the method was verified by repeatability (system precision) and intermediate precision (method precision) studies. Repeatability studies were performed by six replicate injections of $2 \mu \mathrm{g} / \mathrm{ml}$ of Sumatriptan Succinate and $2 \mu \mathrm{g} / \mathrm{ml}$ solution of Naproxen sodium on the same day. The studies were replicated on different days to determine intermediate precision.

\section{Accuracy}

Accuracy of the method was carried out by applying the method to drug sample to which known amount of DOM and NAP standard powder corresponding to 50\%, $100 \%$ and $150 \%$ of label claim had been added (standard addition method), the solutions are analyzed by optimized method.

Limit of detection (LOD) and Limit of quantification (LOQ)

The limit of detection (LOD) is the lowest amount of analyte in a sample that can be detected, but not necessarily quantified, under the stated experimental conditions. LOD \& LOQ was calculated by using standard deviation and slope values obtained from calibration curve.

$\mathrm{LOD}=3.3 \sigma / \mathrm{S}$

$\mathrm{LOQ}=10 \sigma / \mathrm{S}$

Where, $\sigma$ is standard deviation (intercept of calibration line);

$\mathrm{S}$ is slope.

\section{Robustness of the method}

To evaluate robustness of the HPLC method, Slight variations were made in $\mathrm{pH}$ of Mobile phase was changed 6 to 5.8 and 6.2.Slight variations were made amount of organic phase in mobile phase

\section{RESULTS AND DISCUSSIONS}

In the proposed work a HPLC method was developed and validated successfully for simultaneous estimation of Sumatriptan succinate and naproxen sodium. The method utilizes a Reverse Phase C18 column (PhenomenexGemini $250 \mathrm{~mm} \times 4.6 \mathrm{~mm}, 5 \mu \mathrm{m}$ ) with mobile phase of Acetonitrile: Methanol: Phosphate buffer in the ratio of 50:10:40 at $\mathrm{pH} 6$ at the flow rate of $1 \mathrm{ml} / \mathrm{min}$ and $\mathrm{UV}$ detection at $229 \mathrm{~nm}$ for Sumatriptan succinate and naproxen sodium.

The developed method was then validated by using various validation parameters like System suitability, Specificity, Limit of Detection, Limit of Quantification, Linearity, Precision, Accuracy and Robustness as per ICH guidelines. 


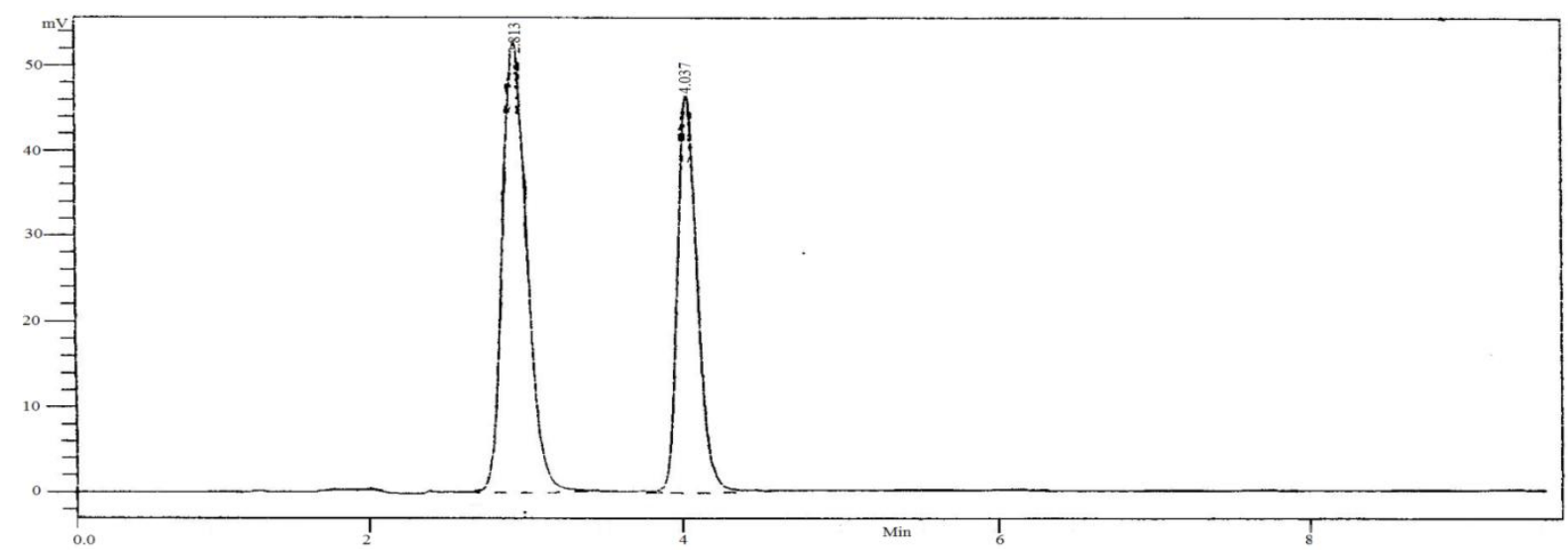

Figure 3: the retention times of Sumatriptan succinate and naproxen sodium were 2.800 and 4.027 min, respectively

In the proposed work a HPLC method was developed and validated successfully for simultaneous estimation of Sumatriptan succinate and naproxen sodium. The method utilizes a Reverse Phase C18 column (PhenomenexGemini $250 \mathrm{~mm} \times 4.6 \mathrm{~mm}, 5 \mu \mathrm{m}$ ) with mobile phase of Acetonitrile: Methanol: Phosphate buffer in the ratio of 50:10:40 at $\mathrm{pH} 6$ at the flow rate of $1 \mathrm{ml} / \mathrm{min}$ and $\mathrm{UV}$ detection at $229 \mathrm{~nm}$ for Sumatriptan succinate and naproxen sodium.

The developed method was then validated by using various validation parameters like System suitability, Specificity, Limit of Detection, Limit of Quantification, Linearity, Precision, Accuracy and Robustness as per ICH guidelines.

Specificity of the method was determined and there was no visible peak in the retention time up to duration of 15 min indicating that the diluent, excipients used in tablet formulation, impurities degradation products and matrix components do not interfere with the peak of Sumatriptan succinate and naproxen sodium, indicating a high degree of specificity for the proposed method.

Linearity of the drugs response was found to be in the concentration range of Sumatriptan succinate and naproxen sodium 1 to $5 \mu \mathrm{g} / \mathrm{ml}$ as the percentage curve fitting for Sumatritan succinate was found to be $99.4 \%$ (correlation coefficient:0.994) and for $99.99 \%$ (correlation coefficient: 0.999) for Naproxen sodium.

The Limit of detection was determined and it was found to be $0.17(\mu \mathrm{g} / \mathrm{mL})$ and $0.18(\mu \mathrm{g} / \mathbf{m L})$ for Sumatriptan succinate and naproxen sodium which indicates that even the small concentrations of the samples can be determined.

The limit of quantification was found to be $\mathbf{0 . 5 3}(\boldsymbol{\mu g} / \mathbf{m L})$ and $\mathbf{0 . 5 3}(\boldsymbol{\mu g} / \mathbf{m L})$ for Sumatriptan succinate and naproxen sodium respectively which indicates that the concentration in micrograms level can be quantified with acceptable accuracy and precision.

Precision of the system and method was determined by replicate injection of standard and sample solution. The $\%$ RSD of peak area for Sumatriptan succinate and naproxen sodium was found to be $0.850 \%$ and $0.881 \%$ respectively which was well within the acceptance criteria for system precision.

Table 2: precision data for Sumatriptan succinate and naproxen sodium

\begin{tabular}{|c|c|c|c|c|}
\hline \multirow{2}{*}{ Sr no. } & \multicolumn{2}{|c|}{ Sumatriptan succinate } & \multicolumn{2}{c|}{ Naproxen sodium } \\
\cline { 2 - 5 } & RT & Peak Area & RT & 292.953 \\
\hline 1 & 2.776 & 324.598 & 4.056 & 294.456 \\
\hline 2 & 2.816 & 326.216 & 4.121 & 296.341 \\
\hline 3 & 2.824 & 324.156 & 3.997 & 291.334 \\
\hline 4 & 2.849 & 320.681 & 4.114 & 289.583 \\
\hline 5 & 2.794 & 322.745 & 4.106 & 295.543 \\
\hline 6 & 2.785 & 328.657 & 4.074 & 293.368 \\
\hline Average & 2.807 & 324.509 & 4.078 & 2.584 \\
\hline S.D. & 0.027 & 2.757 & 0.047 & 0.881 \\
\hline
\end{tabular}

The percentage relative standard deviations (\%RSD) of assay for method precision at three different concentration $(3 \mu \mathrm{g} / \mathrm{ml}, 4 \mu \mathrm{g} / \mathrm{ml}, 5 \mu \mathrm{g} / \mathrm{ml})$ was found to be $1.29,1.42$ and 1.71 respectively for Sumatriptan succinate and $1.31,0.80,0.91$ respectively for Naproxen sodium, which was well within limit of not more than $2.0 \%$. Hence the proposed method was found to provide high degree of precision and reproducibility (Table 1)
The intermediate precision of the method was determined by carrying out the assay by different analyst and by performing the assay on different days to check the reproducibility. The test result were found to be satisfactory with relative standard deviation (\%RSD) for set of analysis on the same day and different days being less than $2.0 \%$ for both Sumatriptan succinate and naproxen sodium and hence the proposed HPLC method is 
found to be Rugged.

Accuracy was determined through recovery studies of the Sumatriptan succinate and naproxen sodium at three different levels 50\%, $100 \%$ and $150 \%$. Sumatriptan succinate and naproxen sodium showed recovery of 99.87 to $101.08 \%$ and 100.11 to $100.80 \%$ ( Table 2) which were found to be well within the acceptance limit of 98-102 $\%$, indicating practically no interference of the drugs with each other or with the excipients present in the formulation for the proposed method indicating that the HPLC method developed for estimation of Sumatriptan succinate and naproxen sodium simultaneously is accurate.

Table 2: Accuracy data for Sumatriptan succinate and naproxen sodium

\begin{tabular}{|c|c|c|c|}
\hline S No. & \%concentration of spiked level & Sumatriptan succinate & Naproxen sodium \\
\hline 1 & $80 \%$ & 100.11 & 100.11 \\
\hline 2 & $100 \%$ & 101.08 & 100.42 \\
\hline 3 & $120 \%$ & 99.87 & 100.80 \\
\hline
\end{tabular}

Robustness of the HPLC method developed was determined by deliberately changing mobile phase ratio and $\mathrm{pH}$ of the mobile phase slightly. The percentage $\%$ RSD of peak area, tailing factor, theoretical plates and resolution were found to be well within the acceptance criteria indicating that the proposed method is robust.

The HPLC method developed and validated for simultaneous estimation of Sumatriptan succinate and naproxen sodium was found to be linear, accurate, precise, stable, rugged and robust.
The proposed method was then applied for determination of Sumatriptan succinate and naproxen sodium in the formulation TREXIMET Tablet. The percentage purity of Sumatriptan succinate and naproxen sodium in tablets was found to be in the range of $98.93 \%$ to $99.62 \%$ and $99.89 \%$ to $101.18 \%$ respectively which was found well within the acceptance limit of 95 to $105 \%$ (Tablet No.III). Hence the HPLC method developed and validated can be routinely used for simultaneous determination of Sumatriptan succinate and naproxen sodium in formulations (tablets).

Table 3: Assay of Sumatriptan succinate and naproxen sodium by RP-HPLC DRUG Sample

\begin{tabular}{|c|c|c|c|c|c|c|c|}
\hline \multicolumn{4}{|c|}{ Sumatriptan succinate } & \multicolumn{4}{c|}{ Naproxen sodium } \\
\hline Conc. & Peak area & Conc. $(\boldsymbol{\mu g} / \mathbf{m l})$ & \% Assay & Conc. & Peak area & Conc. $(\boldsymbol{\mu g} / \mathbf{m l})$ & \% Assay \\
\hline 0.8 & 71.98 & 23.74 & 98.93 & 5 & 1041.18 & 151.78 & 101.18 \\
\hline 0.8 & 72.16 & 23.80 & 99.18 & 5 & 1038.27 & 151.35 & 100.90 \\
\hline 0.8 & 72.48 & 23.91 & 99.62 & 5 & 1027.88 & 149.84 & 99.89 \\
\hline \multicolumn{4}{|c|}{ Average } & 99.24 & \multicolumn{5}{c|}{ Average } & 100.66 \\
\hline
\end{tabular}

These developed methods provide selective quantification of drug without any interference from blank and placebo and are highly sensitive, reproducible, reliable, rapid and specific. Analysis by these methods were found to be simple, accurate, reproducible, precise, and in good agreement with labeled claim of the drug.

Statistical evaluation was carried out on all the developed methods and no significant difference was achieved between the methods. Thus the developed methods can be easily used for the drug analysis in routine quality control

\section{CONCLUSION}

The proposed method was found to be simple, precise, accurate and rapid for simultaneous determination of Sumatriptan succinate and Naproxen sodium. The mobile phase is simple to prepare and economical. The sample recoveries in all formulations were in good agreement with their respective label claims and they suggested noninterference of formulation excipients in the estimation. Hence, the method can be easily and conveniently adopted for routine analysis of Sumatriptan succinate and Naproxen sodium. 


\section{REFERENCES}

1. Ekpe A, Tong JH, Rodriguez L. High-performance liquid chromatographic method development and validation for the simultaneous quantitation of naproxen sodium and pseudoephedrine hydrochloride impurities. J Chromatogr Sci 2001, 39, 81 .

2. Dinc E. Ozdemir A, Aksoy H, Ustundag O, Baleanu D. Chemometric determination of naproxen sodium and pseudoephedrine hydrochloride in tablets by HPLC. Chem Pharm Bull 2006, 54, 415 .

3. Monser L, Darghouth F. Simultaneous determination of naproxen and related compounds by HPLC using porous graphitic carbon column. J Pharm Biomed Anal 2003, 32, 1087.

4. Mitakos A, Panderi I. A validated LC method for the determination of clopidogrel in pharmaceutical preparations. $\mathrm{J}$ Pharm Biomed Anal 2002, 28, 431.

5. Tashtoush BM, Al-Taani BM. HPLC determination of naproxen in plasma. Pharmazie 2003, 58, 614 .

6. Nielsen-Kudsk F. HPLC-determination of some antiinflammatory, weak analgesic and uricosuric drugs in human blood plasma and its application to pharmacokinetics. Acta Pharmacol Toxicol 1980, 47, 267.

7. Phillips TM, Wellner EF. Measurement of naproxen in human plasma by chip-based immunoaffinity capillary electrophoresis. Biomed Chromatogr 2006, 20, 662.

8. Mikami E, Goto T, Ohno T, Matsumoto H, Nishida M. Simultaneous analysis of naproxen, nabumetone and its major metabolite 6-methoxy- 2-naphthylacetic acid in pharmaceuticals and human urine by HPLC. J Pharm Biomed Anal 2000, 23, 917.

9. Zakeri-Milani P, Barzegar-Jalali M, Tajerzadeh H, Azarmi Y, Valizadeh H. Simultaneous determination of naproxen, ketoprofen and phenol red in samples from rat intestinal permeability studies: HPLC method development and validation. J Pharm Biomed Anal 2005, 39, 624.
10. Hsu Y, Liou Y, Lee J, Chen C, Wu A. Assay of naproxen by highperformance liquid chromatography and identification of its photoproducts by LC-ESI MS. Biomed Chromatogr 2006, 20, 787.

11. USP, The United States Pharmacopeia, $24^{\text {th }}$ Edn. The United States Pharmacopeial Convention Inc., Rockville, MD, naproxen sodium monograph, 2006.

12. EP, European Pharmacopoeia, 6th Edn, 2008, Vol.2, p. 3005.

13. USP, The United States Pharmacopoeia, $31^{\text {st }}$ Revision. US Pharmacopoeial Convention Inc. Rockville, MD. 2008, Vol.3 p. 3310.

14. Nozal MJ, Bernal JL, Toribio L, Martín MT, Diez FJ. Development and validation of an LC assay for sumatriptan succinate residues on surfaces in the manufacture of pharmaceuticals. J Pharm Biomed Anal 2002, 30, 285.

15. Ge Z, Tessier E, Neirinck L, Zhu Z. High performance liquid chromatographic method for the determination of sumatriptan with fluorescence detection in human plasma. J Chromatogr B 2004, 806, 299.

16. Vishwanathan K, Bartlett MG, Stewart JT. Determination of antimigraine compounds rizatriptan, zolmitriptan, naratriptan and sumatriptan in human serum by liquid chromatography/electrospray tandem mass spectrometry. Rapid Commun Mass Spectrom 2000, 14, 168.

17. X Xu, M G Bartlett, J T Stewart. Determination of degradation products of sumatriptan. J Pharm Biomed Anal 2001, 26, 367.

18. Cheng KN, Redrup MJ, Barrow A, Williams PN. Validation of a liquid chromatographic tandem mass spectrometric method for the determination of sumatriptan in human biological fluids. J Pharm Biomed Anal 1998, 17, 399.

19. Boulton DW, Duncan GF, Vachharajani NN. Validation and application of a high-performance liquid chromatography/tandem mass spectrometry assay for sumatriptan in human plasma. Biomed Chromatogr 2003, 17, 48. 